\title{
SUBSYSTEM PARTITIONING FOR POWER SYSTEM BLACK-START CONSIDERING RESTORATION RELIABILITY
}

\author{
Haiping Liang
}

Original scientific paper After large scale blackout, there may be more than one black-start unit in power system. A rational subsystem partitioning restoration scheme could speed up the entire system restoration procedure and promote restoration reliability. In the paper, a subsystem partitioning strategy considering the restoration reliability is proposed. The calculation of nodes restoration reliability based on the disjoint of Binary Decision Diagram (BDD) algorithm. Then according to different restoration reliability of nodes to be restored by different black-start units or charged areas, as well as its restoration time of the paths, the belonging subsystems are identified. The proposed subsystem partitioning restoration pays extra attention to the uncertainty of transmission lines and transformers which fits the practical operation conditions better. A partitioning criterion function which is solved by genetic algorithm is established to evaluate the partitioning result. Finally, the effectiveness of the proposed method is validated by IEEE 118 bus system.

Keywords: Binary Decision Diagram algorithm; black-start; minimal path sets; parallel restoration; restoration reliability; subsystem partitioning

Podjela podsustava za crni start energetskog sustava uzimajući u obzir pouzdanost uspostavljanja

Izvorni znanstveni članak Za slučaj nestanka struje velikih razmjera, u energetskom sustavu mogu postojati više od jedne jedinice za crni start. Racionalna shema za obnovu podjele podsustava mogla bi ubrzati čitavi postupak uspostavljanja sustava i pomagati pouzdanost uspostavljanja. U radu se predlaže strategija podjele podsustava uzimajući u obzir pouzdanost uspostavljanja. Proračun pouzdanosti uspostavljanja čvorova zasnovan je na nepovezanosti algoritma binarnog dijagrama odlučivanja. Tada se, prema različitoj pouzdanosti uspostavljanja čvorova koji se trebaju uspostaviti pomoću različitih jedinica za crni start ili odgovarajućih područja, kao i prema vremenu uspostavljanja putanja, prepoznaju odgovarajući podsustavi. Predložena podjele podsustava uspostavljanja posebnu pozornost posvećuje nesigurnosti dalekovoda i transformatora. Funkcija kriterija podjele, koja se rješava genetičkim algoritmom, postavljena je da procijeni rezultat podjele. Konačno, učinkovitost predložene metode potvrđena je sustavom sabirnice IEEE 118.

Ključne riječi: algoritam binarnog dijagrama odlučivanja; crni start; minimalni nizovi putanja; paralelno uspostavljanje; podjela podsustava; pouzdanost uspostavljanja

\section{Introduction}

The black-start in power system is the procedure to recover from a total or partial blackout which has caused an extensive loss of power supplies. With the subsystems interaction becoming more and more intense, it is impossible to exclude the probability that a partial failure may lead to a large scale blackout [1]. The well-known blackouts such as "8.14" blackout in the year 2003 in the U.S. and Canada, the blackout in Brazil power grid on February $4^{\text {th }}, 2011$ [2] and the bulk power network failure in Hainan Island, China, in September, 2005 [3], fully support the viewpoint mentioned above. For bulk power system with a major blackout, there are usually more than one generator unit with self-starting ability in the network. A reasonable subsystem partitioning scheme with smart parallel restoration schemes will greatly speed up the entire system restoration and reduce the risk of the early stage weak system failure.

The partitioning restoration in power system is a complex decision-making control problem considering the power system's dynamic characteristics and its operational constraints. An interconnected bulk power system is usually under the control of several power utilities, therefore, the subsystem partitioning according to their belonging regions is not suitable to solve some operational problems, such as real-time simulation, online security control and optimal network reconfiguration etc. [4]. In reference [5], a black-start subsystem partitioning method based on binary decision program is proposed. It turns the black-start subsystem partitioning problem into a decision problem of Boolean function. But it fails to consider the starting time limits of units. Reference [6] applies the taboo search algorithm based black-start subsystem partitioning strategy, and it integrates the important indexes of the path between nodes and blackstart source, and then the weighted network is established. Based on the target and rules of subsystem partitioning, the target function of taboo search algorithm on the basis of the weight of paths is built, but the units' starting characteristics are neglected. References $[7 \div 9]$ use the genetic algorithm to solve the partitioning problem, and combine the subsystem partitioning strategy with the paths of each restored node and the restore order of each node, together with the network characteristics and units' start-up properties. And the classic shortest path method and the genetic algorithm to get the optimal subsystem partitioning schemes are employed. Reference [10] solves the network partitioning problem with a GN splitting method based on the community structure of complex network theory. In reference [11], a spectral clustering algorithm-based subsystem partitioning algorithm for the black-start is proposed, but the restoration time is not involved in. Thus, the above papers settle the black-start subsystem partitioning problem from different viewpoints and successfully make progress to some degree. However, in the partitioning process, they all fail to take into account the possibility of system restoration failure mainly caused by the uncertainty of transmission lines and the complexity of network structures which greatly affects the reliability of system restoration.

A new black-start subsystem partitioning strategy considering restoration reliability and restoration time is proposed in the paper. Firstly, the successful restoration 
rate of each transmission line in the network is set up. Secondly, based on the disjoint of minimal path sets, the different reliability from a chosen node to be restored to different black-start units or charged areas is calculated. Finally, according to the different restoration reliability from the chosen node to black-start units or charged areas, as well as the restoring time of the path, the belonging area of the node can be identified. By this way, all the nodes can be grouped into suitable subsystems, each with a black-start unit. The network skeleton is formed in each subsystem with higher reliability considering the robustness of network structure and system operation convenience.

\section{Determination of the nodes reliability \\ 2.1 The concepts of minimal path sets (MPS)}

A graph is a collection of vertices (nodes) and edges (arcs), expressed as $G=\{V, E\}$, where $V$ stands for vertices and $E$ for edges. If the edge between tow vertices has a direction, the edge is called a directed edge; otherwise, it is called an undirected edge. A graph composed of directed edges is called a directed graph, and a graph composed of undirected edges is called an undirected graph. A graph with directed edges and undirected edges is called a mixed graph.

A path set is a set of directed or undirected edges which connect two vertices. The minimal path sets are sets of paths in which the two vertices are unconnected from each other if one edge of the path is removed [12].

\subsection{The MPS of a graph}

To determine the MPS of a graph, several methods can be used, such as the searching method, Boolean rowcolumn method and connection matrix method, etc. The connection matrix method is applied in the paper. Multiply the connection matrix by itself repeatedly, until the resulting matrix remains unchanged. Take the following undirected graph shown in Fig. 1 as an example.

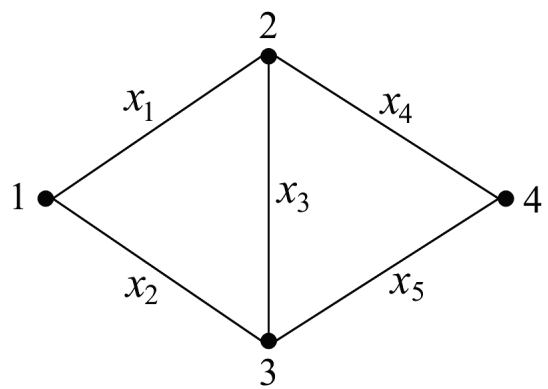

Figure 1 An undirected graph

The connection matrix of the graph in Fig. 1 is:

$$
\begin{aligned}
& \text { To nodes } \\
& \begin{array}{llll}
1 & 2 & 3 & 4
\end{array} \\
& M=\left[\begin{array}{cccc}
1 & x_{1} & x_{2} & 0 \\
x_{1} & 1 & x_{3} & x_{4} \\
x_{2} & x_{3} & 1 & x_{5} \\
0 & x_{4} & x_{5} & 1
\end{array}\right] \begin{array}{l}
1 \\
2 \\
3 \\
4
\end{array} \text { From nodes, }
\end{aligned}
$$

where the rows of the matrix represent "from nodes", the columns of the matrix represent "to nodes". The elements of the connection matrix represent the connection between nodes, the element " 0 " represents no connection between nodes and the element "1" represents connection between a node and itself.

Multiply the matrix by itself repeatedly, then:

$$
M^{2}=\left[\begin{array}{cccc}
1 & x_{2} x_{3} & x_{1} x_{3} & x_{1} x_{4}+x_{2} x_{5} \\
x_{2} x_{3} & 1 & x_{1} x_{2}+x_{4} x_{5} & x_{3} x_{5} \\
x_{1} x_{3} & x_{1} x_{2}+x_{4} x_{5} & 1 & x_{3} x_{4} \\
x_{1} x_{4}+x_{2} x_{5} & x_{3} x_{5} & x_{3} x_{4} & 1
\end{array}\right]
$$

and

$$
M^{3}=\left[\begin{array}{cccc}
1 & x_{1}+x_{2} x_{3} & x_{2}+x_{1} x_{3} & x_{1} x_{4}+x_{2} x_{5}+x_{1} x_{3} x_{5}+x_{2} x_{3} x_{4} \\
x_{1}+x_{2} x_{3} & 1 & x_{3}+x_{1} x_{2}+x_{4} x_{5} & x_{4}+x_{3} x_{5} \\
x_{2}+x_{1} x_{3} & x_{3}+x_{1} x_{2}+x_{4} x_{5} & 1 & x_{5}+x_{3} x_{4} \\
x_{1} x_{4}+x_{2} x_{5}+x_{1} x_{3} x_{5}+x_{2} x_{3} x_{4} & x_{4}+x_{3} x_{5} & x_{5}+x_{3} x_{4} & 1
\end{array}\right]=M^{4}
$$

After multiplying 3 times, the matrix remains unchanged, so the matrix is the MPS matrix.

The minimal path sets between node 1 and node 4 are $x_{1} x_{4}, x_{2} x_{5}, x_{1} x_{3} x_{5}, x_{2} x_{3} x_{4}$.

\subsection{Reliability calculation based on Binary Decision Diagram (BDD)}

The disjoint of minimal path sets is used to calculate network reliability. However, complex calculation is required in the direct disjoint of minimal path sets [13], and thus algorithm will be incompetent when there are too many path sets. With high calculation efficiency, the BDD-based algorithm can be used to calculate the reliability of the network and can make the calculation easier and more effective $[14,15]$. In the paper, the BDD method is used to disjoin the minimal path sets between black-start source and the node to be restored and then the node reliability is computed directly. BDD is a diagram to represent the Boolean function. The diagram has only two types of nodes: the leaf node ( 0 or 1 , representing the constants 0 or 1 ) and the intermediate node (the Boolean variable $x$ ). The decision tree of the network in Fig. 1 is shown in Fig. 2. 


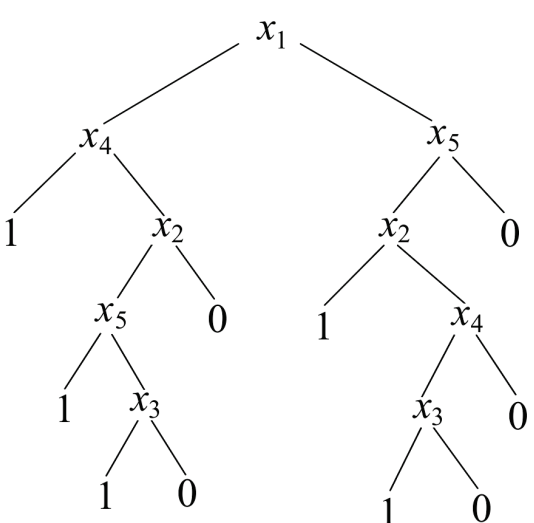

Figure 2 The decision tree of Figure 1

According to the decision tree, the disjoint MPS matrix $\boldsymbol{L}_{\text {dis }}$ can be achieved.

$$
L_{d i s}=\left[\begin{array}{ccccc}
1 & 0 & 0 & 1 & 0 \\
-1 & 0 & 1 & 0 & 1 \\
1 & 1 & 1 & -1 & 0 \\
1 & 1 & -1 & -1 & 1 \\
-1 & -1 & 1 & 1 & 1
\end{array}\right]
$$

The Boolean function is

$$
f=x_{1} x_{4}+\bar{x}_{1} x_{3} x_{5}+x_{1} x_{2} x_{3} \bar{x}_{4}+x_{1} x_{2} \bar{x}_{3} \bar{x}_{4} x_{5}+\bar{x}_{1} \bar{x}_{2} x_{3} x_{4} x_{5},
$$

and the system reliability rate $R_{\mathrm{s}}$ can be calculated by the following Eq. (1):

$$
\begin{aligned}
& R_{\mathrm{s}}=\sum_{i=1}^{n} p\left\{\boldsymbol{L}_{i \text { dis }}\right\}= \\
& p\left(x_{1} x_{4}\right)+p\left(\bar{x}_{1} x_{3} x_{5}\right)+p\left(x_{1} x_{2} x_{3} \bar{x}_{4}\right)+ \\
& +p\left(x_{1} x_{2} \bar{x}_{3} \bar{x}_{4} x_{5}\right)+p\left(\bar{x}_{1} \bar{x}_{2} x_{3} x_{4} x_{5}\right)= \\
& =p_{1} p_{4}+q_{1} p_{3} p_{5}+p_{1} p_{2} p_{3} q_{4}+ \\
& +p_{1} p_{2} q_{3} q_{4} p_{5}+q_{1} q_{2} p_{3} p_{4} p_{5},
\end{aligned}
$$

where $\boldsymbol{L}_{i \text { dis }}$ is the $i^{\text {th }}$ row of the disjoint MPS matrix $\boldsymbol{L}_{\mathrm{dis}}$, $p\left(x_{i}\right)=p_{i}$ is the normal working probability of element $i$ and $p\left(\bar{x}_{i}\right)=q_{i}$ is the probability of failure.

Generally, the system reliability $R_{\mathrm{s}}$ is represented as the following:

$$
R_{\mathrm{s}}=\sum_{i=1}^{n} p\left\{\boldsymbol{L}_{i \mathrm{dis}}\right\}
$$

\section{The subsystem partitioning of power system 3.1 The MPS of power network}

Before applying the MPS theory in the power network analysis, it is necessary to simplify the power network into a graph. The simplification principles are as follows:

(a) All the generator nodes, substation nodes and load nodes are transformed into undifferentiated nodes in the power network topology, and the grounded points are neglected.

(b) All the high-voltage transmission lines and transformer branches are transformed into edges in the graph. The weight of the edges is the restoration time of the branch (transmission lines and transformers).

(c) During the restoration process, in order to reduce the influence of capacitance to earth, for double circuit transmission lines, only one circuit is put into use. Thus in the simplification of power network, double lines can be treated as single lines and the parallel capacitor branches are neglected.

Following the above principles, the original complex power network can be expressed with an undirected graph $G=\{V, E\}$, where $V$ stands for the vertices and $E$ for the branches or edges.

When searching for the minimal path, two searching strategies are usually employed, the depth-first search (DFS) strategy and the breadth-first search (BFS) strategy. In large intricate power networks, for a given starting node and a target node, the BFS method takes large computing and gets many redundant paths. So, it is relatively harder to find the optimal MPS. On the contrary, the DFS method can find out all the connected paths between two points quickly, but for complex network, the results are so many that it is also very difficult to figure out the suitable path sets.

Consequently, this paper employs a bounded depthfirst search method; it works exactly like DFS but avoids its drawbacks by imposing a maximum limit $d$ on the depth of the search. It starts form the starting node, for each step, it checks if the node is the target node, if so, returns, if not, checks if the node is within the maximum search steps. If it reaches the maximum limit without finding the target node, then it automatically drops this path and chooses another path to search. Here, two points need to be clarified: first, the maximum limit $d$ in this paper is determined by the shortest path between two nodes; second, the MPS obtained by this method, does not consist of all the minimal paths between the starting node and the target node, it is just a set of selective paths with relatively shorter restoration time. Considering the urgency of network restoration and the starting time limits of some generator units, the decision made above is reasonable.

\subsection{Determining the restoration successful rate of a node}

In this paper, it is assumed that all the nodes are reliable and only the edges have the possibility of failure. And the successful rate of each line is set to be 0,9 , that is $P\left\{x_{i}\right\}=0,9$. Once the black-start node and target node are determined, we can use the bounded depth-first search method mentioned above to identify the MPS between the two points. The results are kept in matrix $\boldsymbol{L}$.

Because some of the paths in $\boldsymbol{L}$ are crossed, the noncross procedure is used here. The non-crossed paths are kept in the new matrix $\boldsymbol{L}_{\mathrm{dis}}$. The relationship between $\boldsymbol{L}$ and $\boldsymbol{L}_{\mathrm{dis}}$ is as follows:

$$
\boldsymbol{L}_{i \text { dis }} \cap \boldsymbol{L}_{j \text { dis }}=\Phi(i \neq j) .
$$




$$
\bigcup_{i=1}^{n} \boldsymbol{L}_{i \mathrm{dis}}=\bigcup_{j=1}^{m} \boldsymbol{L}_{j \mathrm{dis}} \cdot
$$

As the entire restoration system is a dynamic process, every time when a node is restored, the charged node array should be updated. The next time when seeking the MPS for a following node, it is better to search from all the restored nodes. Consequently, the search for MPS between two nodes is from the charged nodes to a distinct node.

Finally, according to Eq. (2) and the initially set successful probability of transmission lines, the rate of successful restoration for a given node can be calculated.

\subsection{Automatic partitioning of power network}

According to the structure characteristics of power network and the distribution of black-start units, a set of black-start source can be chosen. Then for a given target node, following the method described in part $\mathrm{B}$, the successful rate of being restored by different black-start sources can be obtained, recorded as $P_{s, i}$. Meanwhile, considering the influence of time on the generator's starting status, the partitioning criterion function is established below:

$$
f_{s, i}=\alpha P_{s, i}-\beta T_{s, i}
$$

where $s$ is the label of subsystems; $i$ is the label of the target node; $P_{s, i}$ means the rate of successful restoration by the source in subsystems; $T_{s, i}$ is the average time of node $i$ restored by the source in subsystem $s ; \alpha$ and $\beta$ are weight factors, in the paper $\alpha=0,4, \beta=0,6$, which means in the early stage of power system restoration, time is more important than generator unit's output.

For the same target node, if it is restored by different sources, the values of partitioning criterion function are not the same. Applying generic algorithm, the biggest $f_{s, i}$ is obtained and the corresponding optimal belonging of nodes is identified. Following this way, all the nodes can be divided into different subsystems effectively. In this paper, we mainly deal with the early stage of system restoration after blackout, so only nodes with generator units are chosen as target nodes. Thus, for certain nodes, which are neither generator nodes nor nodes on restoration path, their belonging subsystem cannot be identified.

\section{The design and realization of the algorithm}

The algorithm is designed to two parts. The flow chart of the entire algorithm is shown in Fig. 3. The first part is the initialization, such as inputting all the original data, setting the probability of transmission lines, the simplification of power network and the sorting of generator units according to their starting time limits. The second part is the partition of generator nodes and the identification of restoration path for each node. Based on the content of section III, Matlabcode is realized to calculate the value of partitioning criterion function for each node and to determine the optimal belonging subsystem for it. As for the best path to restore a given node, we select it directly from the MPS which are formerly derived from the procedure of calculating probability of node restoration. The one taking the shortest time is the best one for our target generator node. By this way, all the generator nodes in the network can be effectively divided into different subsystems and the restoration path of each generator node is also determined. Thus, a skeleton network is established in each subsystem.

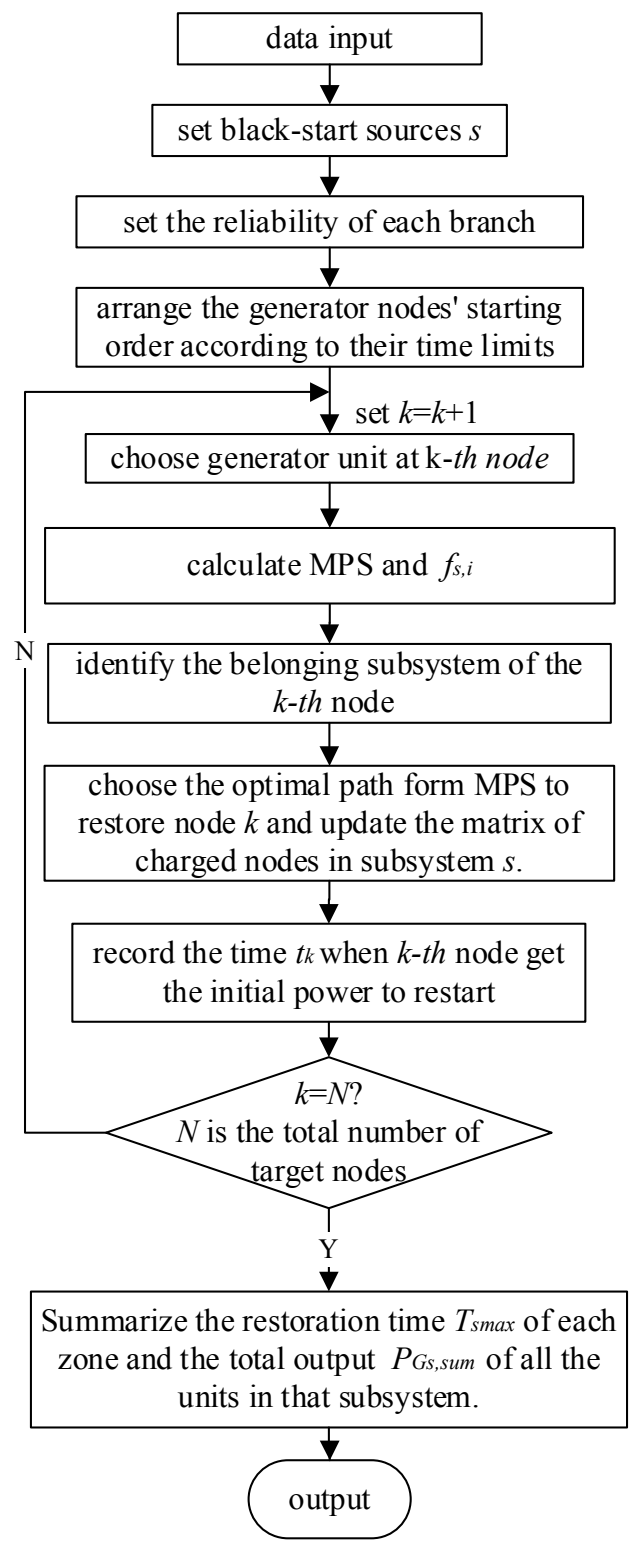

Figure 3 The flowchart of the algorithm

In case of further optimization of this partition procedure, the program complied in this paper is also capable of calculating each subsystem's skeleton restoration time expressed as $T_{s \max }$ and each unit's restarting time. Thus, according to the units' starting time limits and the unit's dynamic restoration model, the total output of the started units $P_{G s \text { sum }}$ in that subsystem can be obtained as well. 


\section{Numerical example test}

Matlab files have been programmed to test the effectiveness of the partitioning strategy proposed in this paper. The IEEE118 bus system is used as a demonstrative example, which has 118 bus nodes, 186 branches (include transmission lines and transformers) and 54 generators in the system. Generator nodes [1 54 99] are set to be the black-start sources. So the system can be partitioned into 3 subsystems. Assuming successful restoration rate, restoration time of branches and start-up time of units are given. RuntheMatlab files and the partitioning scheme can be obtained, which is shown in Tab. 1. The time when the unit restarts and the optimal restoration path for each unit node can be also obtained. Tab. 2 shows the time and sequence of restoration path in subsystem 1. The skeleton network for parallel restoration in the subsystems is shown in Fig. 4.

From the above results it can be seen that, with the method proposed in this paper, a complex power network can be partitioned into several subsystems with the center of black-start nodes. As both the successful rate of node restoration and the time of restoration paths are taken into account, the parallel restoration skeleton network established not only shortens the restoration time but also guarantees the reliability of the network.
Table 1 The system partitioning scheme

\begin{tabular}{|c|c|c|c|}
\hline Subsystem & $\begin{array}{c}\text { Black-start } \\
\text { unit }\end{array}$ & $\begin{array}{l}\text { Time taken } \\
/ \text { min }\end{array}$ & Restored nodes \\
\hline 1 & 1 & 58 & $\begin{array}{c}12,6,4,8,15,10,18,113 \\
31,19,26,32,25,27\end{array}$ \\
\hline 2 & 54 & 56 & $\begin{array}{c}55,56,59,49,61,66,69 \\
62,65,46,42,40,36,116 \\
34\end{array}$ \\
\hline 3 & 99 & 47 & $\begin{array}{c}80,100,92,104,103,77, \\
91,110,105,107,76,89,1 \\
12,90,111,85,74,70,87, \\
24,72,73\end{array}$ \\
\hline
\end{tabular}

Table 2 Time and paths for unit nodes in subsystem 1

\begin{tabular}{|c|c|c|}
\hline Target node & Time to restart & Path \\
\hline 12 & $1-2-12$ & 14 \\
\hline 6 & $1-3-5-6$ & 21 \\
\hline 4 & $5-4$ & 24 \\
\hline 8 & $5-8$ & 25 \\
\hline 15 & $12-14-15$ & 27 \\
\hline 10 & $8-9-10$ & 35 \\
\hline 113 & $12-16-17-113$ & 39 \\
\hline 18 & $17-18$ & 39 \\
\hline 31 & $17-31$ & 42 \\
\hline 19 & $15-19$ & 37 \\
\hline 26 & $8-30-26$ & 47 \\
\hline 32 & $31-32$ & 48 \\
\hline 25 & $26-25$ & 53 \\
\hline 27 & $32-27$ & 58 \\
\hline
\end{tabular}
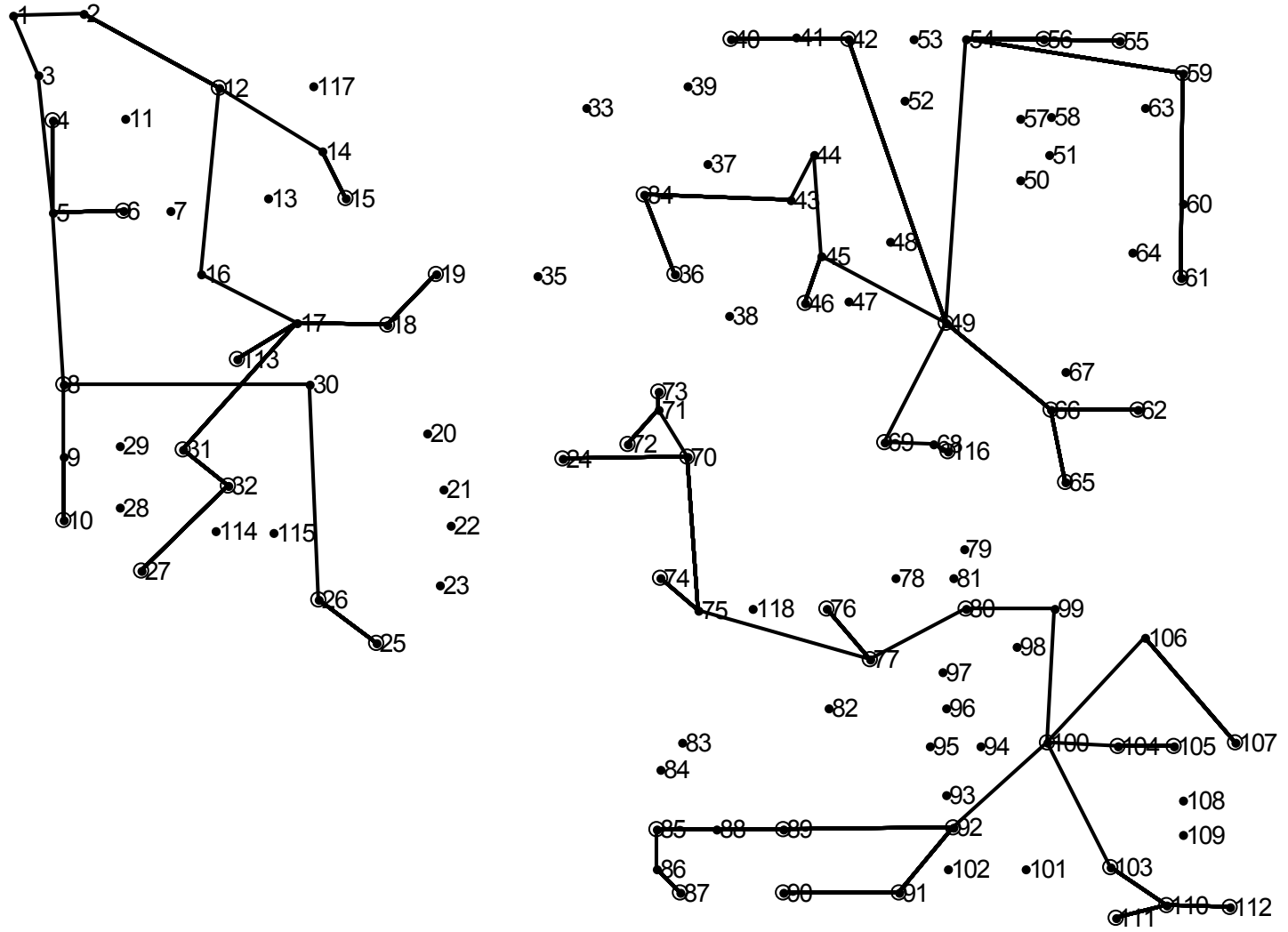

Figure 4 Skeleton network of each subsystem

\section{Conclusion}

A black-start subsystem partitioning strategy considering the reliability of subsystem network skeleton is proposed in the paper. The MPS disjoint based algorithm to calculate the different rates of a target node to be restored by different black-start units (or charged areas) is applied. Combined with the paths restoration time, the partitioning criterion function to determine the belonging subsystem of each generator node is established. The partitioning criterion function is ensured by generic algorithm calculating. Also, by selecting the 
shortest path form MPS, the network skeleton of each subsystem is formed. The results of the IEEE118 test demonstrate that the proposed strategy not only meets the target of black-start restoration, which is to restore unit output as much as possible in the limited time, but also to form a parallel restoration skeleton network with high reliability.

\section{Acknowledgements}

This paper is supported by "the Fundamental Research Funds for the Central Universities (13MS72)".

\section{References}

[1] Xiong, H. M.; Fang, X. Y.; Yu, W. Y.; Liu, S. The Summary of Black-start-restoration of Electrical Power System after Blackout. // Proceedings of the CSU-EPSA.11, 3(1999), pp. 12-17.

[2] Lin, W. F.; Tang, Y.; Sun, H. D.; Guo, Q.; Zhao, H. G.; Zeng, B. Blackout in Brazil Power Grid on February 4, 2011 and Inspirations for Stable Operation of Power Grid. // Automation of Electric Power Systems. 35, 9(2011), pp. 1-8.

[3] Tang, S. Q.; Zhang, M.; Li, J. S.; Wu, X. C.; Jiang, K.; Shu, S. Y. Review of Blackout in Hainan on September $26^{\text {th }}-$ Cause and Recommendations. // Automation of Electric Power Systems. 30, 1(2006), pp. 1-7.

[4] Innocent, K.; Ashok, K. P.; Geza, J. Fuzzy Partitioning of a Real Power System for Dynamic Vulnerability Assessment. // IEEE Transactions on Power Systems. 24, 3(2009), pp. 1356-1365. DOI: 10.1109/TPWRS.2009.2021225

[5] Liu, Y. S.; Wu, W. V.; Feng, Y. Q.; Zhang, B. M.; Yu, N. P. Black-start Zone Partitioning based on Ordered Binary Decision Diagram Method. // Proceedings of the CSEE. 28, 10(2008), pp. 26-31

[6] Wu, Y.; Fang, X. Y.; Zhang, Y.; Yuan, X. F.; Liu, J. T. TabuSearch Algorithm based Black-start Zone Partitioning. // Power System Protection and Control. 38, 10(2010), pp. 6-11.

[7] Orero, S. O.; Irving, M. R. A Genetic Algorithm for Network Partitioning in Power System State Estimation. // IEEE Transactions on Power Systems. 45, 5(1996), pp. 162-165. DOI: 10.1049/cp:19960545

[8] Liang, H. P.; Gu, X. P.; Zhao, D. W. Optimization of System Partitioning Schemes for Power System Black-start Restoration based on Genetic Algorithms. // Power and Energy Engineering Conference / Chengdu, 2010, pp. 1-4.

[9] Gu, X. P; Han, Z. H.; Liang, H. P. Optimization of Parallel Restoration through Power System Partitioning after Blackout. // Proceedings of the CSEE. 29, 10(2009), pp. 4146.

[10] Lin, Z. Z.; Wen, F. S.; Zhou, H. A New Algorithm for Restoration Subsystems Division based on Community Structure of Complex Network Theory. // Automation of Electric Power Systems. 33, 12(2009), pp. 12-16.

[11] Liang, H. P.; Gu, X. P. Black-Start Network Partitioning Based on Spectral Clustering. // Power System Technology. 37, 2(2013), pp. 372-377.

[12] Guo, Y. J. Principles of Reliability Engineering. Tsinghua University Press, 2002.

[13] Clouqueur, M.; Grouver, W. D. Availability Analysis of Span-restorable Mesh Network, Selected Areas in Communication. // IEEE Journal on Selected Areas in Communications. 20, 4(2002), pp. 810-821. DOI: 10.1109/JSAC.2002.1003046

[14] Wu, X. Y. Reliability Modeling and Analysis of Complex Correlative System. // Doctor Thesis, National University of Defence Technology, 2000, pp. 20-30.

[15] Manoj, S.; Chauhan, R. K.; Girish, S. Computing Network Reliability with Imperfect Nodes Using Modified Binary Decision Diagram. // International Journal of Advances in Engineering \& Technology. 3, 2(2012), pp. 606-614.

\section{Authors' addresses}

Haiping Liang, Lecturer

School of Electrical and Electronic Engineering North China Electric Power University, 071003 Baoding, China

E-mail: lianghaiping@aliyun.com 